\title{
Associations Between Unintended Pregnancy, Domestic Violence, and Sexual Assault in a Population of Queensland Women
}

\author{
Leah S. Sharman $^{\mathrm{a}}$ (D), Heather Douglas ${ }^{\mathrm{b}}$ (D), Elizabeth Price ${ }^{\mathrm{c}}$, Nicola Sheeran ${ }^{\mathrm{d}}$ and \\ Genevieve A. Dingle ${ }^{a}$ iD \\ ${ }^{\mathrm{a}}$ School of Psychology, The University of Queensland, St Lucia, QLD, Australia; ${ }^{\mathrm{b}}$ T.C.Beirne \\ School of Law, The University of Queensland, St Lucia, QLD, Australia; ${ }^{\mathrm{c} C h i l d r e n ~ b y ~ C h o i c e, ~}$ \\ Brisbane, QLD, Australia; ${ }^{\mathrm{d}}$ School of Applied Psychology, Griffith University, Mount Gravatt, \\ $Q L D$, Australia
}

\begin{abstract}
This study aimed to establish the proportion of women seeking information regarding unintended pregnancy in the context of domestic violence (DV) and/or sexual assault (SA) experiences in Queensland. Mental health, sociodemographic variables, and gestation at first and repeated contacts were examined for 6249 women primarily seeking information regarding abortion options during an unintended pregnancy over the 5-year period from July 2012 to June 2017. Reports of DV and SA and associations with mental health issues increased significantly across the 5 years. First contact rates of disclosure were $12.2 \%$ for DV and 3\% for SA, and higher among repeat contacts $(38.1 \%$ for DV and $14.1 \%$ for SA), with recurring contact facilitating violence disclosure. Restricting access to abortions in the context of violence impedes a woman's agency in attempts to separate from violence and highlights the need for safe, supportive, and accessible services, to assist in screening and assisting with violence.
\end{abstract}

Keywords: Abortion, domestic violence, sexual assault, unplanned pregnancy.

In Australia, abortion is regulated by individual states and territories, resulting in a patchwork of different legal approaches. Queensland women face the strictest abortion laws in Australia, with regulations left largely unchanged since 1899 (see the Criminal Code Act 1899, sections 224-226 [Qld]). In Queensland, an abortion is lawful if performed in good faith to prevent serious danger to the woman's physical or mental health (Criminal Code Act 1899, s282 [Qld]; R v Bayliss \& Cullen, 1986). Nonetheless, as recently as 2010, a woman and her partner were charged and tried on abortion offences $(\mathrm{R} \mathrm{v}$ Leach \& Brennan, 2010) and in another recent case the Supreme Court was asked to determine whether a 12 year-old girl, despite support for the procedure from her family and treating doctor, should be provided with a termination (Central Queensland Hospital \& Health Service v Q, 2016).

Notwithstanding the legal status of abortion in Queensland, an estimated 10,000-14,000 women do access abortions annually, despite no exact record of the number of abortions performed in Queensland (Health, Communities, Disability Services, Domestic Family Violence Prevention Committee, 2016). Abortion can be difficult to access with many health care providers, including hospitals, refusing to provide this medical care (Portmann, 2008). The Australian Institute of Health and Welfare (AIHW, 2005)

Correspondence: Heather Douglas, T.C. Beirne, School of Law, The University of Queensland, St Lucia, Queensland, 4072 Australia. Email: h.douglas@law.uq.edu.au 
has found that approximately $11.5 \%$ of Queensland women who received terminations of pregnancy in 2003 did so in a different state or territory. It is likely that women leave Queensland for abortions because it is a criminal offence there, but, perhaps more significantly, because health practitioner training in many medical schools does not include clinical or instructional exposure to abortion care, for either medical or surgical termination (Douglas, Black, \& de Costa, 2013; Portmann, 2008; Price, 2015). Consequently, practitioners wishing to become proficient in abortion care need to undertake this training in their own time and at their own cost, further restricting women's access to safe, available, and informed reproductive health care.

Access to abortion in Queensland is made more challenging because of the highly dispersed population, which makes finding a doctor to provide knowledge, support, and qualified care for an abortion particularly difficult. The potential requirement for many women to travel to access such health care can create confusion, increase the cost of care, and compromise the woman's privacy (Fuentes et al., 2016). The need for accessibility and privacy is crucial in cases where pregnancy occurs in the context of domestic violence, where the woman's safety has already been compromised. Unfortunately, many women do attempt to access abortion services because of an unintended pregnancy related to domestic violence and sexual assault (Leung, Leung, Chan, \& Ho, 2002). To date, however, there have been no formal analyses of the prevalence of unintended pregnancy related to domestic violence and sexual assault in Queensland women seeking abortion care.

\section{Unplanned pregnancy and forms of violence}

Domestic violence is defined in section 8 of the Domestic \& Family Violence Protection Act 2012 (Qld). Specifically, domestic violence refers to violent behaviour between current or former intimate partners, including physical, sexual, or emotional abuse, threats and coercion. Globally, more than 1 in 3 women worldwide have experienced domestic or sexual violence (World Health Organization, 2013). Although both women and men are at risk for domestic and sexual violence, in Australia women are almost 3 times more likely to experience these forms of violence than men, with prevalence estimates showing 1 in 6 women reporting domestic or sexual violence from a current or former partner (AIHW, 2018). Despite the alarming rate of violence in Australia, current evidence suggests that domestic, sexual, and emotional abuse against women has remained stable since 2005 , with rates of mental health issues among this group unable to be formerly assessed over this same time period (AIHW, 2018; Chambliss, 2008).

In Australia women who are young, pregnant, separating from a partner, or experiencing financial hardship are more likely to be physically or sexually abused (AIHW, 2018). These forms of violence disproportionately affect women and children in a range of ways, including health, financial, and housing outcomes. Indeed, the leading cause of homelessness in Australia is domestic violence, with $39 \%$ of homeless services clients in 2016-2017 having experienced domestic violence and $94 \%$ of clients being women and children (AIHW, 2018). Domestic and sexual violence have physical, mental, and reproductive health consequences, including posing a significant risk factor for unintended pregnancy, abortion, and repeat abortions (Fanslow, Silva, Whitehead, \& Robinson, 2008; Fisher et al., 2005; Garcia-Moreno, Jansen, Ellsberg, Heise, \& Watts, 2006; Pallitto et al., 2013; Sarkar, 2008). For some women pregnancy is associated with the onset of violence from a formerly non-violent partner, for others there is a continuation or escalation of violence from already violent partners (Campbell, 2002; Karmaliani et al., 2008). Violence during pregnancy has wide-reaching implications for mental health, with increased risk of depression, post-traumatic stress 
disorders, and suicidality among women experiencing violence (Campbell, 2002; Karmaliani et al., 2008).

Some research has indicated the risk for unintended pregnancy is 1.6 times higher for physically abused women and 3.3 times higher for women who experience both sexual and physical violence, compared to those who do not experience any form of violence (Cripe et al., 2008). Unsurprisingly, among those who seek abortions, there is a far greater prevalence of those who have experienced forms of violence $(27 \%)$ than of those who have not $(8 \%$; Coker, 2007; Leung et al., 2002). Because of the controlling nature of the relationships that underpin these forms of violence, women experiencing violence are less able to access health care generally (Plichta, 2004), but are also more likely to terminate their pregnancies at later gestations than women with no experiences of current partner violence (Colarossi \& Dean, 2014; Foster \& Kimport, 2013; Taft \& Watson, 2007). This can pose significant barriers for the woman, depending on the regulation of late term termination of pregnancy where she resides. In circumstances where an abortion is wanted but denied due to restricted access or illegality, women are more likely to resort to unsafe abortion methods or to continue with pregnancies that risk maternal death (De Costa, 2005; WHO, 2016).

\section{The current study}

This study seeks to understand the broader context and risk factors for women in Queensland experiencing unplanned pregnancies and who have sought information regarding pregnancy options, including abortion services. In particular, the main aim of this study is to establish the proportion of women seeking unplanned pregnancy options in the context of domestic violence and/or sexual violence at initial or repeated contact, and whether this rate has changed over the 5-year period between July 2012 and June 2017. Given the available literature, we predicted that for Queensland women:
1. The proportion of women seeking information regarding unintended pregnancy and access to abortion services experiencing domestic violence and/or sexual assault over the 5-year period of available data should be stable.

2. Mental health problems would be higher among women seeking abortions who had experiences of domestic violence and/or sexual assault, compared to those who had not.

3. Women who reported experiences of domestic violence and/or sexual assault will be more likely to be single or separated rather than being in a current relationship.

4. Women experiencing domestic violence and/or sexual assault will be more likely to seek abortion services later in their gestation than women not experiencing domestic violence and/or sexual assault.

Rates of mental health issues in this population are also explored over the 5-year period. Because of the limited literature concerning adolescents and young adults seeking abortions, this was explored within the data where the data were available.

\section{Method}

The following data were collected in the 5 years between July 2012 and June 2017 by an independent Brisbane-based non-profit organisation that provides unbiased information on unplanned pregnancy options (abortion, adoption, and parenting), post-abortion counselling, and support to access an abortion, if requested.

\section{Nature of service and data collection}

The information used in this article was gathered by counsellors in their contacts with or on behalf of women seeking support in relation to an unplanned or unwanted pregnancy. Counsellors record each session independently and without any identifiers of the woman to protect her privacy. These sessions record 
Table 1. Number of initial and repeated contacts on the part of women and external service calls made on behalf of a woman within each year.

\begin{tabular}{lcccc}
\hline & \multicolumn{2}{c}{ Women } & \multicolumn{2}{c}{ External services } \\
\cline { 2 - 5 } Year & Initial & Repeat & Initial & Repeat \\
\hline $2012 / 13$ & 1184 & 531 & 355 & 396 \\
$2013 / 14$ & 1255 & 507 & 257 & 270 \\
$2014 / 15$ & 1345 & 1050 & 259 & 634 \\
$2015 / 16$ & 1183 & 1536 & 266 & 1058 \\
$2016 / 17$ & 1282 & 1492 & 179 & 757 \\
\hline
\end{tabular}

either the absence or presence of a range of issues and barriers from what is known about the woman's circumstances at each contact with the service. There is a thorough counselling practice across each stage of intake, assessment, intervention, and evaluation.

The data are captured by individual contacts as either the 'first contact' or a 'repeated contact'; however, due to the lack of identifying information collected, it is not possible to link data from each contact to any individual woman. That is, multiple contacts to the service may be made in relation to a single woman and pregnancy. As such, we cannot accurately report variables in terms of proportion of women, but only in terms of the number of contacts made to the service. Therefore, we have taken care and caution in analysis and interpretation of the data in this paper.

This research will also explore, where relevant, patterns emerging from contacts to the service by external service providers on behalf of women. These providers are defined as a contact from external government departments, non-government organisations, community agencies, hospitals, clinics, medical agencies, and sexual health services. External agency contacts in this report are discussed according to the first contact with the service - that is, the first contact with the organization on behalf of a woman experiencing an unwanted pregnancy.

\section{Participants}

Across the 5 years, 6249 women seeking information regarding termination of pregnancy were recorded at first contact with the service. The number of total 'repeated' contacts with the service (those not including first contacts) were 5116. First contacts by service providers on behalf of a woman across all years were 1316, and repeated contacts were 3115 . See Table 1 for total number of contacts of each group within each year. From all recorded contacts (both first and repeat contacts), the majority of contacts were regarding abortion, with $67.1 \%$ regarding abortion information and $3.2 \%$ of all contacts regarding post-abortion counselling. Only $2 \%$ of women were seeking information about adoption and $6.6 \%$ contacted regarding parenting information; $39.3 \%$ of women contacted regarding unplanned pregnancy counselling. Of all the women who made initial contact, 288 identified as Aboriginal or Torres Strait Islander and 467 identified as culturally or linguistically diverse. Ages were recorded in ranges and extended from under 13 to over 45 years, with the median age recorded at first contact between 20 and 24 years (see Figure 1). From the available postcode data, women made contact from across the state, far beyond the major cities, including the top end of Queensland at Cape York and remote central and western corners of Queensland.

\section{Results}

Because of the various imitations in the data set, significance testing was conducted only in relation to a woman's first contact with the service to ensure significance testing of results 


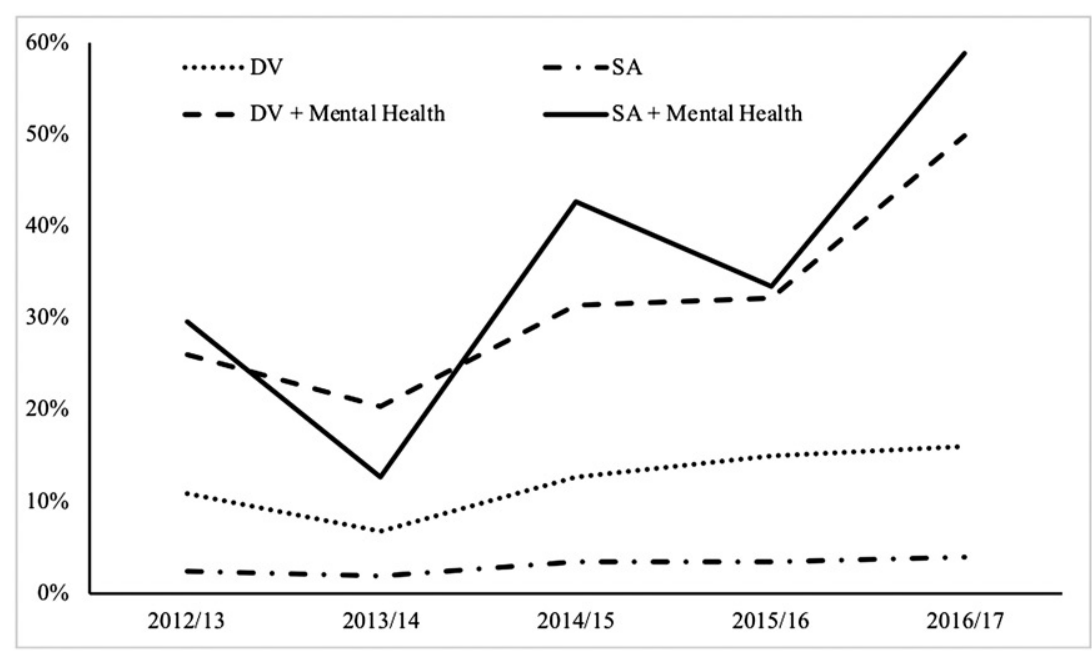

Figure 1. Percentage of contacts disclosing domestic violence (DV), sexual assault (SA) and co-occurring mental health issues associated with an unintended pregnancy over 5 years.

was not inflated. A series of chi-square tests were performed to analyse the binary data set overall, and across time. All other results were compared via overall percentages when any data were compared at repeat contacts, external service contacts, or when data were collected at ordinal levels for gestation. For the following data, disclosure of domestic violence (DV), or sexual assault (SA) related to the current pregnancy were analysed separately. Although sexual violence was included in domestic violence screening, sexual assault was noted separately if the presenting pregnancy was thought to have occurred through non-consensual sex.

\section{Unintended pregnancy and associations with violence}

Among first contacts with all women, there appears to be an increase in disclosure of DV from $10.6 \%$ in $2012 / 13$, to $16 \%$ in $2016 / 17$, $\chi^{2}(1, N=2466)=15.15, p<.001$. Disclosure of SA also displayed an increase over time from $2 \%$ to $4 \%$ over the same period, $\chi^{2}(1, N=2466)=5.79, p=.02$, see Figure 1 for rates of disclosure over the 5 -year period. Adolescents and young adults aged 19 and under over this time period showed no differences between years for disclosures of DV, $\chi^{2}(1, N=244)=0.58, p=.45$, or SA, $\chi^{2}(4$, $N=244)=0.20, p=.66$.

Overall disclosure of DV across the years for first contacts with the service was $12.2 \%$ for DV and 3\% for SA. For repeat contacts with the service a much higher prevalence of disclosure was apparent, at $38.1 \%$ for DV and $14.1 \%$ for SA across the 5-year period (see Figure 1 for a comparison of first and repeated contacts). There was considerable overlap between experiences of violence in this sample, with $55 \%$ of women who disclosed sexual assault also disclosing experiences of domestic violence at first contact. The disclosure rate with external agencies that had initial contact with the organisation was lower on average than at first contact with the woman, with $10.9 \%$ having knowledge of DV and, surprisingly, no reports of SA.

\section{Mental health}

Mental health issues are determined by counsellors if the woman discloses a pre-existing diagnosed mental health condition. Although uncommonly noted, any diagnosed mental health condition of the woman's partner involved with the pregnancy is also noted within the same criteria. Counsellors have 


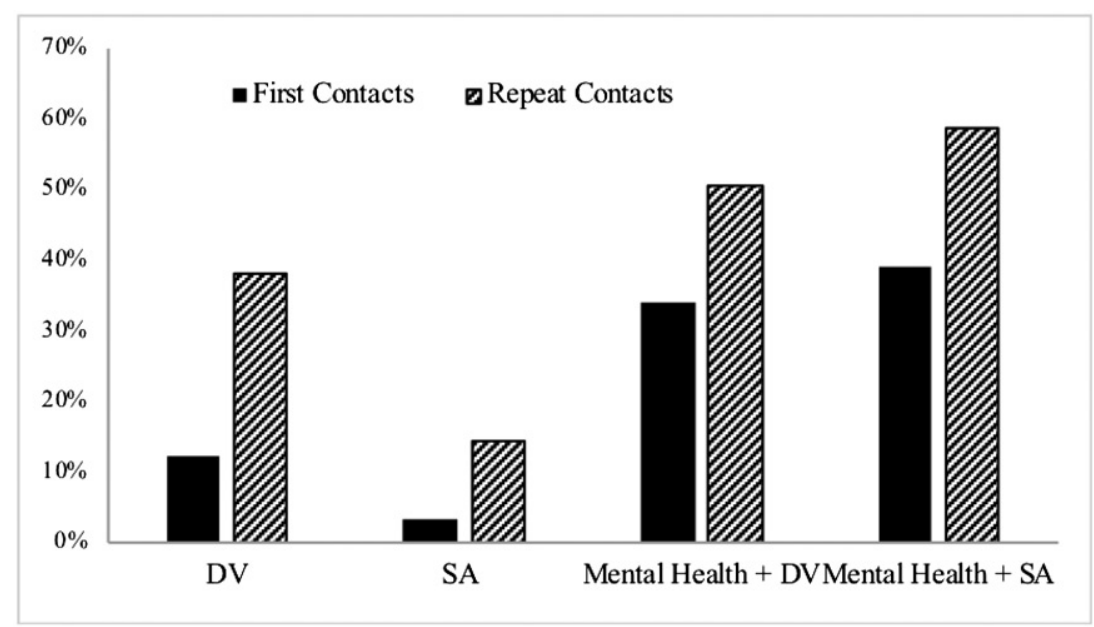

Figure 2. Percentage of contacts disclosing domestic violence (DV), sexual assault (SA) and co-occurring mental health issues associated with an unintended pregnancy at first and repeated contacts.

noted that mental health of the partner is rarely noted, and when it is, it usually co-occurs with the woman's own mental health condition. The prevalence for mental health issues among this sample of Queensland women substantially increased, from $11.2 \%$ of all women at first contact in 2012 to $20 \%$ in $2017, \chi^{2}(1$, $N=2466)=35.35, p<.001$. Women who had repeated contact with the service had even greater disclosure, comparatively, with $21 \%$ in 2012 to $48 \%$ in 2017. Across the 5 years, approximately $13 \%$ of women disclosed mental health issues at initial contact with the organisation, compared with $35 \%$ of women who called more than once. Over the 5-year period, of women who suffered domestic violence and disclosed this at initial contact, on average, $34 \%$ also disclosed a mental health issue, and this significantly increased from $26 \%$ in 2012 to $50 \%$ in $2017, \chi^{2}(1$, $N=331)=17.94, \quad p<.001 . \quad$ Similarly, of women who disclosed sexual assault at initial contact with the organisation, $39 \%$ also disclosed a mental health issue on average over the same period, significantly increasing from $30 \%$ in 2012 to $59 \%$ in $2017, \chi^{2}(1$, $N=331)=6.02, p=.01$, see Figure 1 for rates of disclosure across the 5-year period.

Mental health issues for women at initial contact with the service were significantly higher for women who had disclosed DV (34\%) compared to those who disclosed mental health issues in the absence of DV (10\%), $\chi^{2}(1, N=6249)=368.27, p<.001$. Similarly, for SA, women at initial contact and who disclosed mental health issues were disproportionately more likely to also disclose SA (39\%) compared to not $(12 \%), \quad \chi^{2}(1$, $N=6249)=124.75, p<.001$. Of women who called the organisation more than once, on average, $50.5 \%$ of women reported both DV and mental health issues, and $58.4 \%$ reported both SA and mental health issues over the 5 years (see Figure 2 for a comparison of first and repeated contacts). Initial contacts for external agencies were the same for both DV and SA on average for knowledge of co-occurring mental health issues at $35 \%$.

\section{Relationship status}

Recorded relationship status of women experiencing unplanned pregnancy at initial contact with the organisation, overall, was most likely for women who were in a continuing relationship (34\%), then for those who were single or separated (26\%), and least likely for those in casual relationships $(4 \%)$; the remainder of women did not record relationship status or were placed under 'other', so were not 


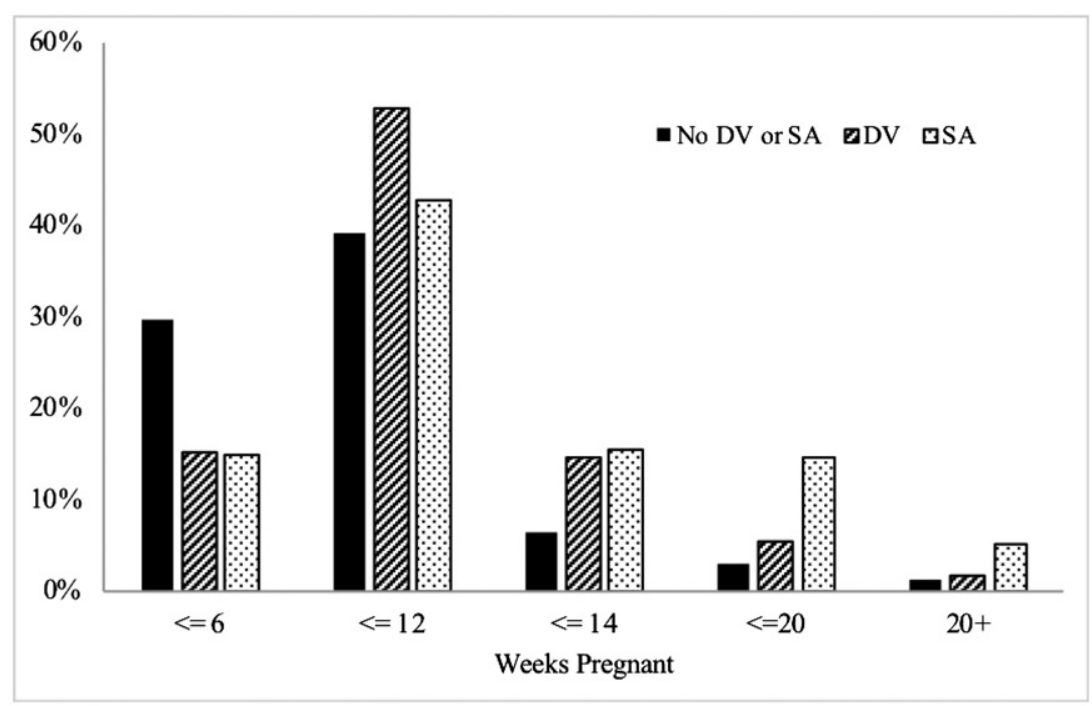

Figure 3. Number of weeks pregnant at first contact and association with domestic violence (DV) or sexual assault (SA)

analysed. Of those who disclosed DV, 75\% were single or separated and $22 \%$ were married or in an ongoing relationship. Of those who had no experience of DV, $60 \%$ were married or in ongoing relationships, $34 \%$ were single, and $7 \%$ were in a casual relationship, $\chi^{2}(2, \quad N=4007)=421.10, \quad p<.001$. Of women with disclosure of SA at first contact with the organisation, $81 \%$ were single or separated, $17.4 \%$ were married or in an ongoing relationship, and $1 \%$ were in a casual relationship. Comparatively, for women with no disclosure of SA, $54 \%$ were in a relationship, $39 \%$ were single, and $6 \%$ were in casual relationships, $\chi^{2}(2, N=4007)=108.62, p<.001$ (see Figure 3).

\section{Gestation at contact}

Women who disclosed DV at initial contact with the organisation were most likely to contact the service between 7 and 12 weeks' gestation, with $53 \%$ of women disclosing DV calling during this period. Women with no disclosure of DV were also most likely to make contact between 7 and 12 weeks' gestation, with $39 \%$ of these women calling during this period of pregnancy. However, women who did not disclose DV were also more likely to call at 6 weeks or less of gestation, with $30 \%$ calling earlier in the pregnancy compared to only $15 \%$ of women with disclosure of DV. Women who did not disclose DV were also less likely to call at later stages of pregnancy, with only $11 \%$ of women contacting the organisation after 12 weeks' gestation compared to $22 \%$ of women who disclosed experiences of DV (see Figure 4.).

Similarly, women who disclosed SA were most likely to contact the service at between 7 and 12 weeks' gestation, with $43 \%$ of women calling during this period. Again, only $15 \%$ called when gestation was 6 weeks or less. Women with no disclosure of SA also made the most calls to the organisation at between 7 and 12 weeks' gestation (41\%), but they were also more likely to call the organisation earlier, at 6 weeks or less in the pregnancy (28\%). Women without SA disclosure were also less likely to call later than 12 weeks, with only $12 \%$ of calls made at this later stage of pregnancy compared to $30 \%$ of women who disclosed SA (see Figure 2). 


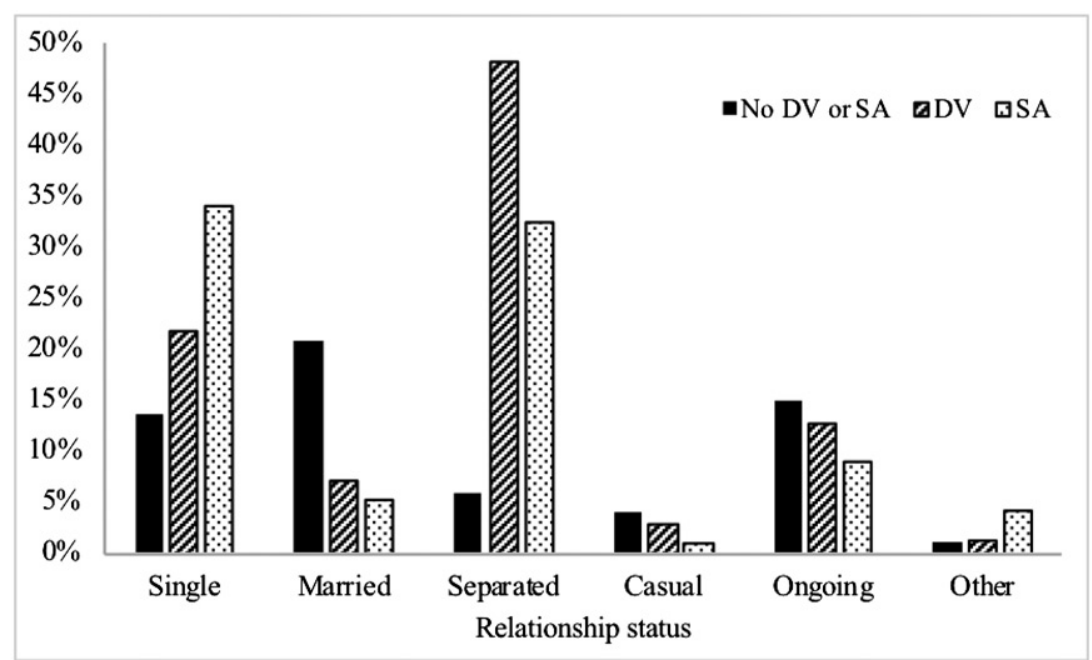

Figure 4. Relationship status of women at first contact with disclosure of domestic violence (DV) and sexual assault (SA)

\section{Discussion}

\section{Forms of violence and rates of mental health}

Our results found a clear relationship between women experiencing forms of violence and attempts to access information regarding unplanned pregnancy options. However, contrary to our prediction that proportions would remain stable, there was an increase between July 2012 and June 2017 in the proportion of Queensland women seeking unintended pregnancy options who disclosed experiences of domestic violence or sexual assault. Our results differ from those reported by the AIHW (2018), which reported a stable rate of partner violence, emotional abuse, and sexual assault against Australian women between 2005 and 2016.

Rates of disclosure of mental health issues also increased over the 5-year period, with over half of women reporting co-occurring mental health and domestic violence or sexual assault between July 2016 and June 2017. As predicted, the incidence of mental health problems was higher among women seeking abortions who had experienced violence than among those who had not. Overall, in this study more than 1 in 3 of Queensland women who disclosed domestic violence or sexual assault also disclosed some form of mental health issue.

It is important to consider other potential contributing factors related to this increase in reporting domestic violence, sexual assault and mental health issues found within our sample. These include an upsurge in awareness of these issues among the wider population and an attempt to reduce stigma in the Australian context via advertising and awareness campaigns by the government and domestic violence services (AIHW, 2018). Notably, these increased rates of disclosure may be associated with an interplay of stigma reduction, awareness, and a comfortable and supportive relationship with experienced counsellors who repeatedly ask questions regarding experiences of violence and control (Hague \& Sardinha, 2010). This interaction among significant variables relating to understanding and support of experiences of violence is likely to have led to increases in disclosure of issues that have historically been under-reported (AIHW, 2018).

Low rates of identification of domestic violence over the 5-year period were notable among external agencies contacting the service 
on behalf of the woman. Identification of domestic violence to other government and health agencies was reported as much lower than by women who contacted the service directly at first contact, suggesting that these organisations were less likely to ask the woman about violence or, if violence was present, decided not to disclose this information. A further lack of identification of violence among these women is clear in the data, with no reports of sexual assault of the woman from any external government or health agency contact. Quite unsurprising, however, was the higher number of women disclosing forms of violence and mental health issues when they had more than one contact with counsellors at the service, rather than at first contact alone. Having numerous contacts gives the woman opportunities to develop a relationship with counsellors and to disclose important information. These proportions should be interpreted with caution, however, as they are subject to inflation from disproportionate contacts from individual women.

\section{Relationship and gestation status}

In line with predictions, our results indicate that, generally, women seeking advice regarding unintended pregnancies and access to abortion services were most likely to be in a continuing relationship. However, those who disclosed forms of violence were considerably more likely to be single or separated than those in a continuing relationship. It was also clear that regardless of whether violence was present, generally women who called the service called most often when gestation was estimated to be between 7 and 12 weeks. However, those women for whom violence was a factor tended to seek services less often at earlier stages of pregnancy and more often after 12 weeks' pregnancy than those who made no disclosure of violence.

A disproportionately higher number of women who report experiences of violence seek access to information regarding unintended pregnancy and access to abortion services in Queensland compared to women who report no forms of violence. Women who reported violence also reported significantly more mental health issues than did women who did not disclose domestic or sexual violence. This suggests that forms of violence against women and mental health issues are and continue to be significant factors in unintended pregnancy and attempts to access abortion services. Previous research indicates that women experiencing violence are more likely to seek termination of pregnancy to remove themselves from violent relationships and to avoid bringing children into an abusive environment (Chibber, Biggs, Roberts, \& Foster, 2014; Ely \& Murshid, 2017). While most coercion involves pregnancy promotion, some women in abusive relationships are also at risk for coercion into abortions, often with threats to end the relationship if the pregnancy is not terminated, which we were unable to assess within our data (Moore, Frohwirth, \& Miller, 2010; Silverman et al., 2010).

A compounding factor for Queensland women experiencing violence is the time it takes to access health care. Unsurprisingly, given the controlling nature of domestic violence, including the abuser's control of reproductive health and finances, women who experience forms of violence appear to take longer to access reproductive health services. This can compromise access to abortion care and significantly increase its care and costs (Foster \& Kimport, 2013). Later attempts to access abortion services may result from the abuser's controlling behaviour, and delay may be further exacerbated because of the time women need to remove themselves from the relationship before being able to access help (Chibber et al., 2014; Fuentes et al., 2016).

\section{Conclusion}

There is a pervasive concern of under-reporting of domestic violence and sexual assault and this has often hampered efforts in obtaining and interpreting data in this area (AIHW, 
2018). From our data it is clear there is a large difference in disclosing instances of domestic violence and sexual assault when contact is first made with a woman seeking support and information around her unplanned pregnancy. Indeed, the results of our analysis stress an approach of "ask soon, ask often" and the importance of this approach in all health care and service areas, alongside creating a supportive environment for disclosure. It is also clear that more needs to be done to prevent violence against women and to assist women who are attempting to leave violent circumstances. Given the control and intimidation that surrounds domestic violence, preventing and restricting access to abortions in these instances only reduces and, in some cases, removes the woman's agency in her attempts to separate from a difficult and dangerous situation.

\section{Ethical standards}

\section{Declaration of conflicts of interest}

Leah Sharman has declared no conflicts of interest

Heather Douglas has declared no conflicts of interest

Elizabeth Price has declared no conflicts of interest

Nicola Sheeran has declared no conflicts of interest

Genevieve Dingle has declared no conflicts of interest.

\section{Ethical approval}

This article does not contain any studies with human participants or animals performed by any of the authors.

The research looked at de-identified statistical data collected by workers at Children By Choice (rather than working directly with human participants). This research has received ethical approval from the Griffith University Human Research Ethics Office and the University of Queensland Human Ethics Research Office [2017001882/HREC/2017/
892] and the research was carried out consistently with the terms of ethical approval.

\section{Funding}

This work was supported by the BEL Faculty Collaborative Seeding Grant, University of Queensland 2018; and an Australian Research Council Future Fellowship [Grant FT140100796].

\section{ORCID}

Leah S. Sharman (D) http://orcid.org/00000003-1989-6380

Heather Douglas (D) http://orcid.org/00000002-0420-3820

Genevieve A. Dingle (D) http://orcid.org/00000002-4915-169X

\section{References}

Australian Institute of Health and Welfare (AIHW). (2018). Family, domestic and sexual violence in Australia 2018. Retrieved from https://www. aihw.gov.au/reports/domestic-violence/familydomestic-sexual-violence-in-australia-2018/ contents/table-of-contents

Campbell, J. C. (2002). Health consequences of intimate partner violence. The Lancet, 359, 1331-1336. http://doi.org/https://doi.org/10. 1016/S0140-6736(02)08336-8

Central Queensland Hospital and Health Service v Q. (2016). Central Queensland Hospital and Health Service v Q (by her Litigation Guardian). QSC 89.

Chambliss, L. R. (2008). Intimate partner violence and its implication for pregnancy. Clinical Obstetrics \& Gynecology, 51(2), 385-397.

Chibber, K. S., Biggs, M. A., Roberts, S. C. M., \& Foster, D. G. (2014). The role of intimate partners in women's reasons for seeking abortion. Women's Health Issues, 24(1), e131-e138. Retrived from http://doi.org/10. 1016/j.whi.2013.10.007

Coker, A. L. (2007). Does physical intimate partner violence affect sexual health? Trauma, Violence, \& Abuse, 8(2), 149-177. Retrived from http://doi.org/10.1177/1524838007301162

Colarossi, L., \& Dean, G. (2014). Partner violence and abortion characteristics. Women 
and Health, 54(3), 177-193. Retrived from http://doi.org/10.1080/03630242.2014.883662

Criminal Code Act. (1899). Criminal Code Act 1899 (QLD). Retrieved from https://www. legislation.qld.gov.au/view/pdf/inforce/current/ act-1899-009

Cripe, S. M., Sanchez, S. E., Perales, M. T., Lam, N., Garcia, P., \& Williams, M. A. (2008). Association of intimate partner physical and sexual violence with unintended pregnancy among pregnant women in Peru. International Journal of Gynecology and Obstetrics, 100(2), 104-108. http://doi.org/ 10.1016/j.ijgo.2007.08.003

de Costa, C. M. (2005). Medical abortion for Australian women: It's time. Medical Journal of Australia, 183(7), 378-380.

Domestic and Family Violence Protection Act. (2012). Domestic and Family Violence Protection Act. (Q1d).

Douglas, H., Black, K., \& de Costa, C. (2013). Manufacturing mental illness (and lawful abortion): doctors' attitudes to abortion law and practice in new South Wales and Queensland. Journal of Law and Medicine, 20(3), 560-576.

Ely, G., \& Murshid, N. (2017). The association between intimate partner violence and distance traveled to access abortion in a nationally representative sample of abortion patients. Journal of Interpersonal Violence, 2017, 1-27. Retrieved from http://doi.org/ 10.1177/0886260517734861

Fanslow, J., Silva, M., Whitehead, A., \& Robinson, E. (2008). Pregnancy outcomes and intimate partner violence in New Zealand. Australian and New Zealand Journal of Obstetrics and Gynaecology, 48(4), 391-397. Retrieved from http://doi. org/10.1111/j.1479-828X.2008.00866.x

Fisher, W. A., Singh, S. S., Shuper, P. A., Carey, M., Otchet, F., MacLean-Brine, D., ... Gunter, J. (2005). Characteristics of women undergoing repeat induced abortion. Canadian Medical Association Journal, 172(5), 637-41. Retrieved from http://doi. org/10.1503/cmaj.1040341

Foster, D. G., \& Kimport, K. (2013). Who seeks abortions at or after 20 weeks? Perspectives on Sexual and Reproductive Health, 45(4), 210-218. Retrieved from http://doi.org/10. $1363 / 4521013$

Fuentes, L., Lebenkoff, S., White, K., Gerdts, C., Hopkins, K., Potter, J. E., \& Grossman, D. (2016). Women's experiences seeking abortion care shortly after the closure of clinics due to a restrictive law in Texas.
Contraception, 93(4), 292-297. Retrieved from http://doi.org/10.1016/j.contraception. 2015.12.017

Garcia-Moreno, C., Jansen, H. F. M., Ellsberg, M., Heise, L., \& Watts, C. H. (2006). Prevalence of intimate partner violence: Findings from the WHO multi-country study on women's health and domestic violence. Lancet, 368, 1260-1269. Retrieved from http://doi.org/10. 1016/S0140-6736(06)69523-8

Hague, G., \& Sardinha, L. (2010). Violence against women: Devastating legacy and transforming services. Psychiatry, Psychology and Law, 17(4), 503-522. http://doi.org/10.1080/13218711003709410

Health, Communities, Disability Services, and Domestic Family Violence Prevention Committee. (2016). Abortion law reform (Woman's Right to Choose) amendment bill 2016 and inquiry into laws governing termination of pregnancy in Queensland. Retrieved from http://www.parliament.qld. gov.au/documents/tableOffice/TabledPapers/ 2016/5516T1337.pdf

Karmaliani, R., Irfan, F., Bann, C. M., McClure, E. M., Moss, N., Pasha, O., \& Goldenberg, R. L. (2008). Domestic violence prior to and during pregnancy among Pakistani women. Acta Obstetricia et Gynecologica Scandinavica, 87(11), 1194-1201. Retrieved from http://doi.org/10.1080/ 00016340802460263

Leung, T. W., Leung, W., Chan, P. L., \& Ho, P. C. (2002). A comparison of the prevalence of domestic violence between patients seeking termination of pregnancy and other gynecology patients. International Journal of Gynecology \& Obstetrics, 77(1), 47-54.

Moore, A. M., Frohwirth, L., \& Miller, E. (2010). Male reproductive control of women who have experienced intimate partner violence in the United States. Social Science and Medicine, 70(11), 1737-1744. Retrieved from http://doi.org/10.1016/j.socscimed.2010.02.009

Pallitto, C. C., Garcia-Moreno, C., Jansen, H. a. F. M., Heise, L., Ellsberg, M., \& Watts, C. (2013). Intimate partner violence, abortion, and unintended pregnancy: Results from the WHO Multi-country Study on Women's Health and Domestic Violence. International Journal of Gynecology \& Obstetrics, 120(1), 3-9. Retrieved from http://doi.org/10.1016/j. ijgo.2012.07.003

Plichta, S. B. (2004). Intimate partner violence and physical health consequences: Policy and practice implications. Journal of 
Interpersonal Violence, 19(11), 1296-1323. Retrieved from http://doi.org/10.1177/ 0886260504269685

Portmann, C. (2008). Therapeutic abortion provision: Abortion in Queensland conference report. Brisbane, Queensland.

Price, J. (2015, November 23). Doctors not developing skills, understanding necessary to provide abortions. The Sydney Morning Herald. Retrieved from https://www.smh. com.au/opinion/doctors-not-developing-skillsunderstanding-necessary-to-provide-abortions20151123-gl5rnu.html

R v Bayliss and Cullen. (1986). 9 QLD Lawyer Reps 8 ('Bayliss')

R v Leach and Brennan. (2010). QDC 329 (Cairns)

Sarkar, N. N. (2008). The impact of intimate partner violence on women's reproductive health and pregnancy outcome. Journal of Obstetrics and Gynaecology, 28(3), 266-271. Retrieved from http://doi.org/10. 1080/01443610802042415

Silverman, J. G., Decker, M. R., McCauley, H. L., Gupta, J., Miller, E., Raj, A., \&
Goldberg, A. B. (2010). Male perpetration of intimate partner violence and involvement in abortions and abortion-related conflict. American Journal of Public Health, 100(8), 1415-1417. Retrieved from http://doi.org/ 10.2105/AJPH.2009.173393

Taft, A. J., \& Watson, L. F. (2007). Termination of pregnancy: Associations with partner violence and other factors in a national cohort of young Australian women. Australian and New Zealand Journal of Public Health, 31(2), 135-142. Retrieved from http://doi. org/10.1111/j.1753-6405.2007.00031.x

World Health Organization (WHO). (2013). Global and regional estimates of violence against women: Prevalence and health effects of intimate partner violence and nonpartner sexual violence (WHO publication No. 978924156462 5). Retrieved from http://www.who.int/reproductivehealth/publications/violence/9789241564625/en/

World Health Organization (WHO). (2016). Preventing unsafe abortion. Retrieved from http://www.who.int/mediacentre/factsheets/ fs $388 /$ en/ 